\title{
Loess and Bee-eaters IV: distribution of the Rainbowbird (Merops ornatus Latham 1801) in Australia
}

Ian Smalley, Sue McLaren, Ken O'Hara-Dhand Giotto Loess Research Group, Geography Department, Leicester University, Leicester LE1 7RH, UK (ijs4@le.ac.uk)

"Some of the most important variables for habitat choice are the physical characteristics of soil in banks used for bee-eater breeding colonies."

P.Heneberg \& K.Simecek 2004

\begin{abstract}
The first three papers in the Loess and Bee-eaters series sought to establish links between the nesting of bee-eater birds (family Meropidae) and the occurrence of loess deposits. For the European bee-eater there is a close and fairly obvious relationship; for the Carmine bee-eater nesting in the $15 \mathrm{~N}$ band of Africa more assumptions and adjustments have to be made, and for the Blue-cheeked bee-eater nesting in the Indus region the relationship is becoming vague and more speculative. The trend continues with the Australian bee-eater- the Rainbowbird (Merops ornatus). We lack precise maps of loess distribution in Australia and there is an equal lack of detailed and accurate maps of the distribution of rainbowbird nesting.

Loess in Australia is elusive; the maps of Kriger and Scheidig show little detail and are essentially contradictory. If the deterministic theory of loess deposit formation were applied it would suggest that loess should
\end{abstract}


be found in the region where Pleistocene cold-phase mountain glaciers occurred. In the last glacial phase there was very little glacial occurrence in Australia; probably a limited region near Mount Kosciuszko. This places some glacial activity in the extreme south east of the country. This agrees, more or less, with the data on the Kriger map.

Fry has mapped the breeding zones of the Rainbowbird and they are concentrated in the south east and south west. The maps are not precise but there does seem to be indications of co-existence of bee-eater nests and loessic regions. This is not the clearcut relationship which has been observed with the European bee-eater but it is suggestive. The ill-defined loess/dust regions and the poorly demarcated nesting zones of the rainbowbird do seem to be coincident. Better mapping is urgently required for loess in Australia, and nesting zones of Merops ornatus. It may be that dust rather than loess is the ground material to be observed in Australia. There are still problems of integrating the dust and loess concepts, but mapping of dust deposits does produce some coincidence with rainbowbird nesting. The region of Vertisol occurrence appears to be a barrier to the spread of rainbowbird nesting.

Keywords: Loess, Bee-eater birds, Rainbowbird, Australia, constraints on nesting tunnels, loess and dust in Australia.

\section{Introduction}

In a hole in the ground there lived a rainbowbird (Merops ornatus Latham 1801). All the members of the bee-eater family (the Meropidae) breed in tunnels in the ground. As Fry stated in the seminal monograph on the bee-eaters "All bee-eaters nest in earth holes" (Fry 1984 p.17) and the Australian bee-eater, the rainbowbird, is no exception. Many authors and authorities refer to this bird as the Rainbow bee-eater but Fry consistently calls it the Rainbowbird. We follow Fry, the great authority on the Meropidae, and call it the rainbowbird. 
It lives all over Australia but has a relatively restricted nesting zone. We propose that the limits of the nesting zone are, to a large extent, set by the properties of the ground. This is a study of ground and its suitability for bee-eater nesting. The idea that the nature and properties of the ground are a major control of nesting is largely down to Heneberg (2009, 2013, Heneberg \& Simecek 2004) and it was he who pointed out the interaction of the two key properties of ground strength and excavateability. The ground must be strong enough to support the tunnel but it must have properties that allow the birds to build a nesting tunnel. The Heneberg compromise demarcates the interaction of these two factors (see Smalley et al $2013 a, b)$. Because of this propensity for tunnel building the study of the Meropidae falls into two disciplines: ornithology and soil mechanics. Most writings on beeeaters concern habits and distribution and evolution and fall into the field of ornithology, but there is a small parallel field of study which is concerned with the properties of the ground.

The bee-eater appears to favour loess ground; the silty, open-structured, airfall deposits of loess fit the Heneberg requirements better than other grounds. This has been studied in Europe where there is a plentiful supply of loess and an abundance of bee-eaters (see Kerenyi \& Ivok 2013, Sepiol et al 2012, Smalley et al 2013b). If the ground is so ideal and so totally favoured by bee-eaters it may be that a concentration of bee-eater nests should suggest the existence of loess ground. On the basis of this rather tenuous assumption the bee-eater/loess relationship has been examined, with reference to Africa (McLaren et al 2014), and the Indian sub-continent (Smalley et al 2015).

The rainbowbird is widespread in Australia; it is an important and iconic bird (fig.1). It is observed across the country and has been closely examined (see e.g. Lill \& Fell 2007). The Fry distribution maps place its breeding regions in the extreme east, and to the south west, and these appear to be the regions where loess or other 
favourable ground might be expected. The bee-eaterground relationship might be better observed in Australia than in other places because the birds live all over the country but only choose to nest in certain regions. There is only one species of bee-eater to observe and it has a whole variety of terrains to choose from for nest building. We consider two initial maps of ground and feature distribution, by Kriger(1965) and Scheidig (1934). Both are inadequate but are the only reliable examples of world-over loess mapping.

\section{Kriger (1965)}

Kriger presented a world map of loess deposit distribution to the $6^{\text {th }}$ INQUA Congress in the USA in 1965 (Kriger 1965 p.37). A version of the Australia section of this map is shown in fig.2. This map has to be speculative and based on assumptions. Kriger had no direct knowledge of Australian terrain and access to virtually no literature. He chose to put the region of loessic interest into the east and the south-east; a region of some high ground and some involvement in possibly glacial events. The Kriger map has 6 zonal markers but only 3 were required for Australia, and no loess was actually shown. The implication in fig. 2 is that a small amount of glacial action may produce an associated loess deposit.

\section{Scheidig (1934)}

This is in many ways a much superior map to that of Kriger, although it was published much earlier. Scheidig used a projection of the Mercator-type which tended to emphasize the mid-latitude regions; which is, of course, where most loess is found. Scheidig divided loess deposits into two types: definite (nachgewiesen) and possible/probable (wahrscheinlich oder möglich) and it is this latter type that he indicates in Australia (fig.3). The distribution shown in fig. 3 looks strange and eccentric. As in the Kriger situation the cartographic data has to be somewhat speculative. This Scheidig map could be more misleading than useful. For most of the world it is undoubtedly adequate and was used by Woldstedt (1954) in his major study of the Quaternary Era. Woldstedt 
presented the Scheidig map with small alterations (mit geringfugigen Anderungen) but did not significantly change the possible loess in Australia. Scheidig may be accurate in the south-west(the Yilgarn area)- this is certainly a region of interest.

Scheidig did comment on the Australian situation (Scheidig 1934 p.26). "Auch in Australien mussen Losse, und zwar eiszeitliche wie kontinentale, vermutet warden." (roughly translated: there could be glacial and continental loess in Australia). He was aware of the possibility of loess in Australia, but he lacked the resources to accurately map it.

\section{Fry (1984)}

Fry (1984 pl.6) used data from the Atlas of Birds of Australia (RAOU 1984) to plot a distribution map for rainbowbird nesting in Australia. It shows a concentration in the south-east and south, and the south-west (the Yilgarn region), and a few isolated locations(fig.4a). The Fry map is a rather approximate map; the Atlas data on which it is based is shown in fig.4b. The maps give a general impression of the location of rainbowbird breeding (see RAOU 1984 p.333).

\section{Soil map}

Fig. 5 is a simple soil map of Australia, based on the USDA Soil Taxonomy system. Soil Orders are indicated; it is a very basic soil map. The Alfisols appear to be favoured zones. They are certainly favoured by humans, these are productive soils and have high agricultural value. They contain sufficient silt to give a good soil structure, to allow root penetration and drainage, and to provide nutrients. Silt tends to deliver nutrients. The Vertisol band in Queensland and New South Wales is a clay rich region. These are the classic expansive soils, they contain enough clay minerals of the smectite type to display considerable dimensional change on wetting and drying. Their clayey nature would tend to make them unsuitable for bee-eater nesting. Where the birds intrude into a Vertisol region it may be that fluvial processes have introduced enough material to modify ground nature. The Vertisol region may 
represent a real zoogeographic barrier; comparison of the soil map and the breeding distribution map suggests that this might be the case.

\section{Relief map}

A relief map with very little detail is shown in fig.6. This indicates land over $600 \mathrm{~m}$ in elevation, and a portion of the drainage network. The high ground is in the south-east. The highest mountain, Mount Kosciuszko at $2228 \mathrm{~m}$, is there in the Great Dividing Range. If there was to be mountain loess produced in the Last Glacial Maximum this is the logical region for occasional mountain glaciers to occur. A reasonable scenario has a few mountain glaciers producing a moderate amount of silt which stayed concentrated in the south east region, contributing to the local alfisols and generally improving soil texture.

7. Discussion: Loess and Dust in Australia.

Some discussions on loess have focussed on desert loess and mountain loess and the possibilities of loess in Australia (Smalley \& Derbyshire 1990, Yaalon 1991, Haberlah, 2007, 2008, Smalley 2008). The Area definition of loess (Smalley \& Derbyshire 1990), to some extent, underpins much fundamental loess discussion, and explores the idea of mountain loess.

A modest amount of mountain loess might be expected in Australia, but as fig. 6 shows there are few large mountains. The so-called deterministic approach to loess deposit formation can offer a sensible sequence from mountain glacier to loess deposit, via river and aeolian transportation. If there were mountain glaciers in the highest part of Australia during the time of the last glacial maximum then it is likely that they produced loess material, and that this material formed small local deposits and/or was incorporated into local soils. The Alfisols in the south-east could contain loess material. The addition of loess material does improve the agricultural performance of a soil. The Alfisols in Middle England benefit from an addition of loess material. 
An alternative to loess deposits for bee-eater nesting might be the difficult-to-define (loess in all but name) dust deposits. A large part of the discussion by Haberlah(2007) was a call for other types of loess deposit to be recognised, and Hesse \& McTainsh (2003) made the same proposal. Haberlah was aware that there was very little traditional loess in Australia, but that there were silty deposits which possessed many of the attributes of loess. These dust deposits have been reviewed and discussed by Hesse \& McTainsh(2003). They proposed that the bestdocumented aeolian dust deposits are those in the Eastern Highlands (zone $\mathrm{C}$ in fig.7) of central and southern New South Wales. They pointed out that the recognised Australian dust mantles have field characteristics in common with loess, particularly their massive earthy fabric, and suggested that there was no good reason, to exclude these deposits from the broad range of the term loess. In Australia it would appear that the bee-eaters agree.

The 'parna' of Butler (1956) is essentially loess in which the role of the glacially produced quartz silt has been replaced by silt-sized clay aggregate particles formed in and around lakes. Australian lakes can make silt sized, clay rich dust, and this can form loessic deposits. Fig.8. shows the distribution of dust deposits sited in the southeast region, after Butler(1982). Compare fig. 8 with fig. 4 to see a good coincidence of bird tunnels with dust deposits.

8. Discussion: the Rainbowbird in Australia Bastian et al(2013) have studied the distribution of the European bee-eater in Germany and noted local concentrations, although no particular attempt was made to relate ground type to bird concentration. It was noticeable however that certain loess-rich Lander were favoured. In Australia it might be possible to extend the range of ground factors which affect the nesting of holeliving birds. Heneberg has emphasised the positive effects of the presence of loess ground and demonstrated the relationship of ground texture to nesting efficiency. In 
Australia it may be possible to indicate a clearly negative ground factor, essentially the presence of clay minerals. We propose that the western boundary of the main nesting zone is set by the presence of that great band of Vertisol soil which separates the mountains from the desert. Vertisols are expansive soils, they have large amounts of clay minerals, and these clay minerals are usually of a very clayey variety, the smectites, mostly montmorillonite. A soil from close to the southern limit of the vertisol band was studied by Smalley \& Xidakis (1979) who found a high concentration of montmorillonite. This produces a very cohesive soil, one which the rainbowbirds would find very difficult to utilise.

A speculative view of fig. 4 suggests that the nests possibly follow rivers. River bank material is much favoured by hole-nesting birds and the silty material could be carried out of the high regions and deposited in river banks. Look for bee-eaters in the dusty deposits of the Yilgarn in the south-west and in Murray-Murrumbidgee catchment of the south-east, where Bruce Butler mapped the dust.

\section{Conclusions}

It appears that ground materials do affect the nesting of the rainbowbirds in Australia. They appear to favour a silty ground, where the Heneberg compromise works in their favour. This could be silty ground of a loessic or dusty nature. The plot of dust deposit distribution has a good match to the map of bird breeding zones. The high clay content of very clayey smectite clays in vertisols may constrain the nesting region; soils which are very clay-rich and cohesive are not suitable for tunnel construction.

\section{References}

Bastian, A., Bastian, H-V., Fiedler, W., Rupp, J., Todte, I., Weisss, J. 2013. Der Bienenfresser (Merops apiaster) in Deutschland- eine Erfolgsgesichte. Fauna Flora RheinlandPfalz 12(h3) 861-894. 
Butler, B.E. 1956. Parna-an aeolian clay. Australian Journal of Science 18. 141-151.

Butler, B.E. 1982. The location of aeolian dust mantles in south-eastern Australia. In R.J.Wasson (ed.) Quaternary Dust Mantles of China, New Zealand and Australia.

Australian National University Press 141-144.

Fry, C.H. 1984. The Bee-Eaters. T \& A.D. Poyser London 304p.

Haberlah, D. 2007. A call for Australian loess. Area 39, 224-229.

Haberlah, D. 2008. Response to Smalley's discussion of 'A call for Australian loess'. Area 40, 135-136.

Heneberg, P. 2009. Soil penetrability as a key factor affecting nesting of burrowing birds. Ecological Research 24, 453-459.

Heneberg, P. 2013. Decision making in burrowing birds: Sediment properties in conflict with biological variables. Quaternary International 296, 227-230.

Heneberg, P., Simecek, K. 2004. Nesting of European bee-eaters (Merops apiaster) in Central Europe depends on the soil characteristics of nest sites. Biologia, Bratislava $59,205-211$.

Hesse, P.P., McTainsh, G.H. 2003. Australian dust deposits: modern processes and the Quaternary record. Quaternary Science Reviews 22, 2007-2035.

Kerenyi, Z., Ivok, E. 2013. Nestsite characteristics of the European Bee-eater (Merops apiaster $L$ ) in the Gödöllö Hills. Ornis Hungarica 21(2), 23-32.

Kriger, N.I. 1965. Loess- its characteristics and relation to the geographical environment. Nauka Moscow 296p (in Russian). 
Lill, A., Fell, P.J. 2007. Microclimate of nesting burrows of the Rainbow Bee-eater. Emu 107, 108-114.

McLaren, S., Svircev, Z., O'Hara-Dhand, K., Heneberg, P., Smalley, I.J. 2014. Loess and bee-eaters II: The 'loess' of North Africa and the nesting behaviour of the Northern Carmine Bee-eater (Merops nubicus Gmelin 1788). Quaternary International 334/5, 112-118.

RAOU 1984. The Atlas of Australian Birds (Royal Australian Ornithological Union) ed. M.Blakers, S.J.J.F.Davies, P.N.Reilly. Melbourne University Press $750 p$.

Scheidig, A. 1934. Der Loss und seine geotechnischen Eigenschaften. Theodor Steinkopff Dresden u.Leipzig 233p.

Sepiol. B., Dudzik, K., Mandziak, M. 2012. Breeding population of the European bee-eater Merops apiaster in the Sandomierz Upland 2001-2012. Naturalia 1, 71-86 (in Polish, Engl. summary).

Smalley, I.J. 2008. A call for Australian loess: discussion and commentary. Area 40, 131-134.

Smalley, I.J., Derbyshire, E. 1990. The definition of icesheet and mountain loess. Area 22, 300-301.

Smalley, I.J., Xidakis, G.S. 1979. Thermogravimetry of an expansive clay soil from Adelaide; approximate mineralogical analysis using standard montmorillonites. Clay Science 5, 189-193.

Smalley,I.J., Smalley, G., O'Hara-Dhand, K., Jary, Z. 2013a. Sand Martins favour loess: how the properties of loess ground facilitate the nesting of Sand Martins/ Bank Swallows/ Uferschwalbenn (Riparia riparia L 1758). Quaternary International 296, 216-219. 
Smalley, I.J., O'Hara-Dhand, K., McLaren, S., Svircev, Z., Nugent, H. 2013b. Loess and bee-eaters I: Ground properties affecting the nesting of the European bee-eater (Merops apiaster L.1758) in loess deposits. Quaternary International 296, 220-226.

Smalley, I.J., McLaren, S., O'Hara-Dhand,K. 2015. Loess and bee-eaters III: Birds and ground in the Punjab and the Indus region. Quaternary International- in press.

Woldstedt, P. 1954. Das Eiszeitalter Bd.1. Enke Stuttgart 362p.

Yaalon, D.H. 1991. Mountain loess is not a suitable term. Area 23, 255-256.

Figures

1. The Rainbowbird (Merops ornatus ); also known as the Rainbow bee-eater. Observed over all of Australia, but not Tasmania.

2. Details of Australia from the Kriger (1965) map of world loess distribution. The regions demarcated are the zone affected by modern cold conditions (the largest region); the periglacial zone and the very small region of actual glaciation (on the Mainland and in Tasmania). Kriger puts no actual loess in Australia.

3. The loess deposits in Australia, after Scheidig (1934). This is possible loess, and has to be very speculative. No justification for the observed pattern was offered.

4. Nesting distribution of the rainbowbird in Australia. (a) map based on Fry (1984). Fry used data from the RAOU Atlas of Australian Birds. The asterisks indicate isolated observations. There is a large concentration of nesting activity in the east and the 
south-east, but also a significant region in the south-west. (b) the Atlas data used by Fry: the dot size relates to observed frequency (RAOU 1984 p.333).

5. Soil map of Australia. A simple soil map based on USDA Soil Taxonomy data. The regions are demarcated at the Sub-order level but are only labelled at the Order level: A Alfisols, D Aridisols, E Entisols, $V$ Vertisols, $U$ Ultisols, $X$ soils in areas with mountains.

6. Relief. A very simple relief map; the only regions shown are those over $600 \mathrm{~m}$ in altitude; and a portion of drainage. The location of Mount Kosciuszko(2228m) is indicated.

7. Regions in which dust deposits have been identified (after Hesse \& McTainsh 2003). A, Southern coast; $B$, Inland basins; C, Eastern Highlands and coastal fringe, including Tasmania; D, Inland Ranges, including the Cobar Block; E, Yilgarn region.

8. Dust deposits in the south-east, after Butler (1982) The square symbols indicate reported occurrences of significant dust deposits. This is a dust region, and a bee-eater region. 


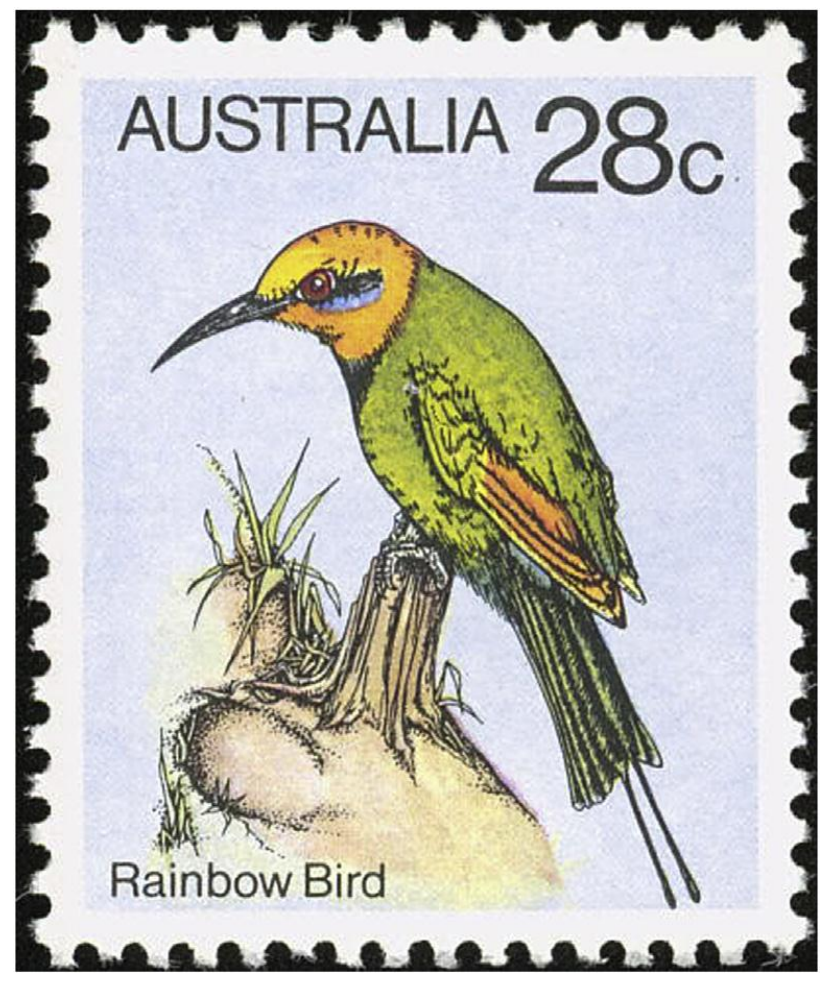

Fig 1

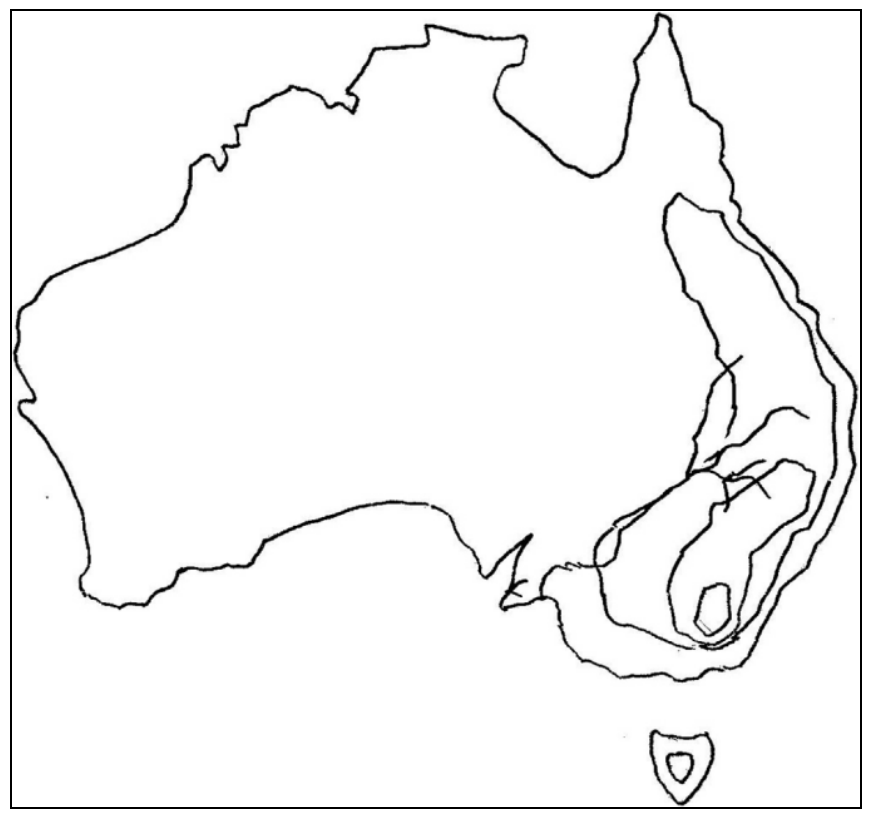

Fig 2 


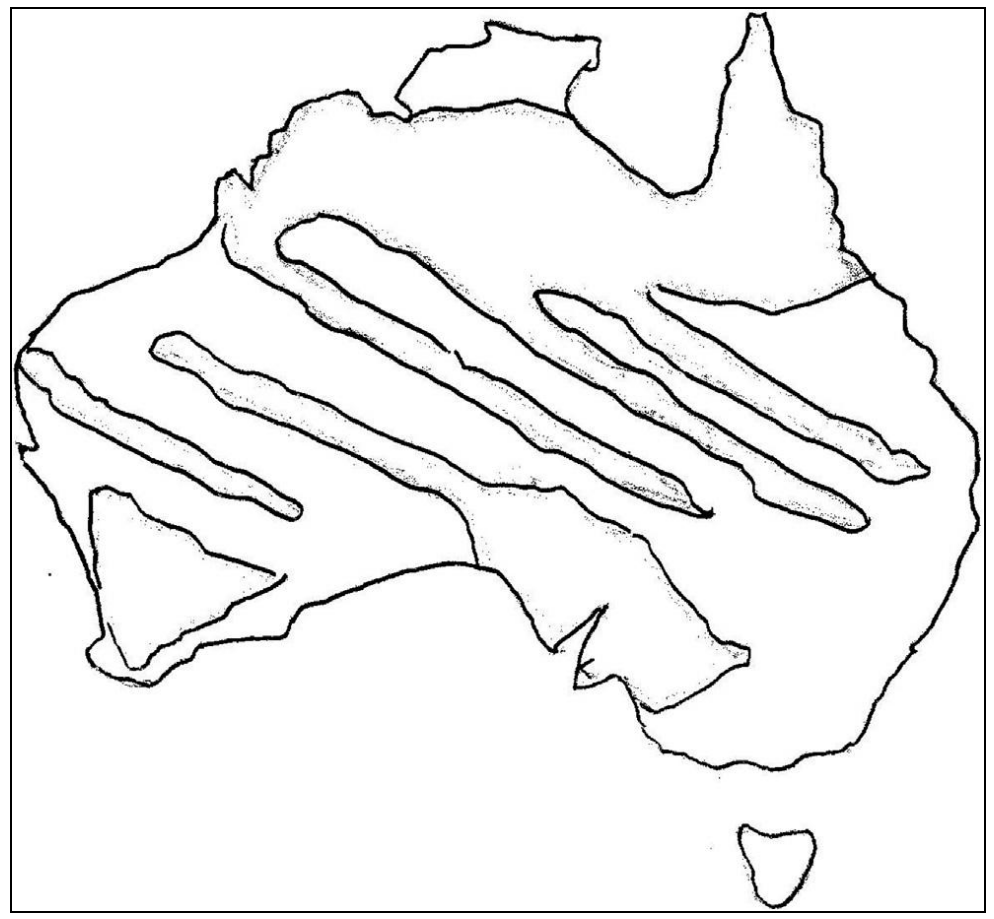

Fig 3

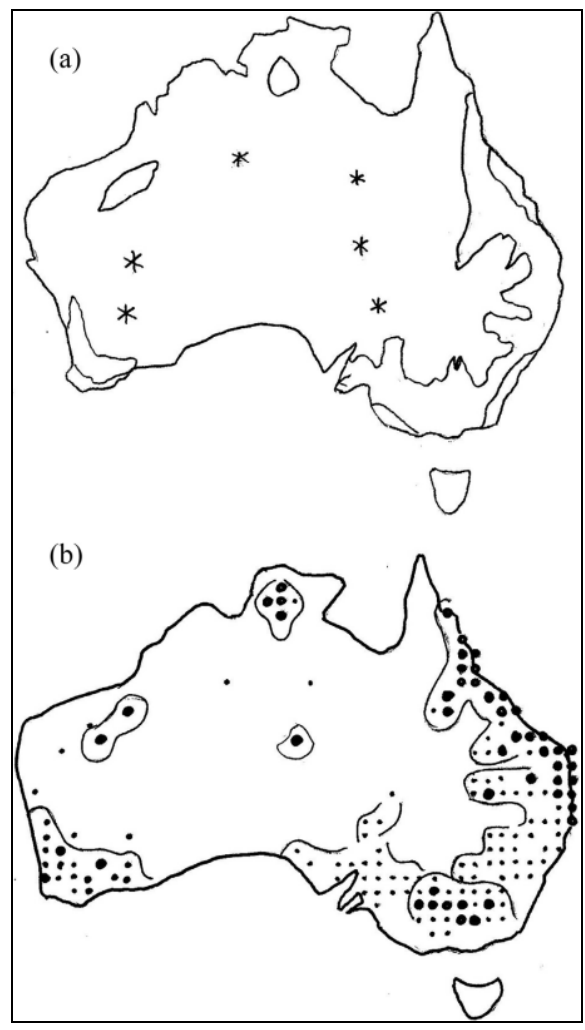

Fig 4 


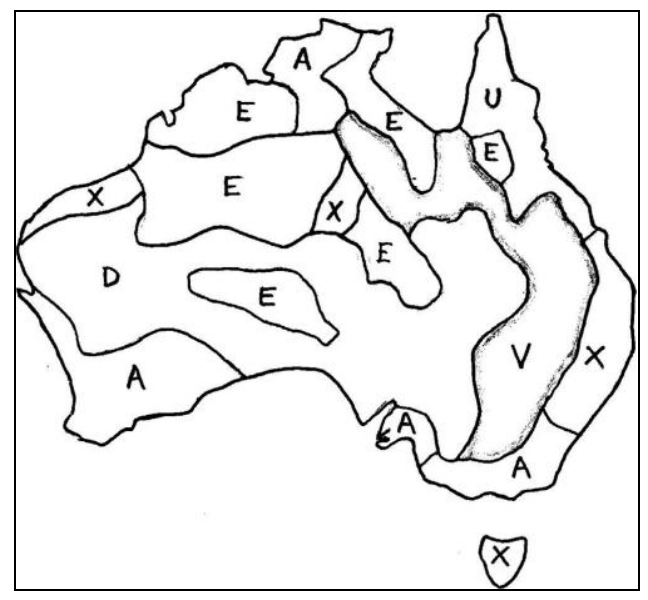

Fig 5

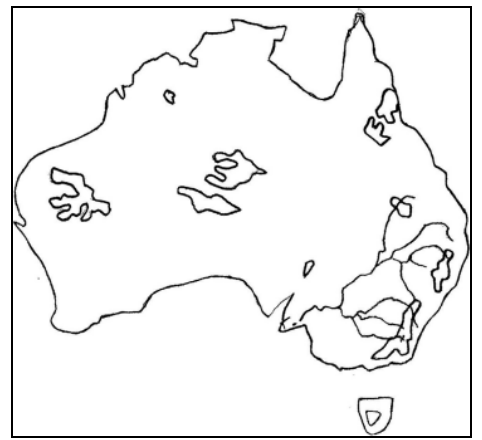

Fig 6

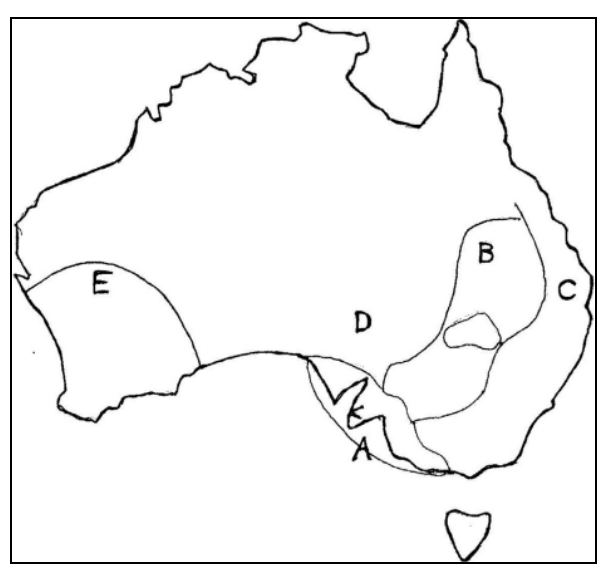

Fig 7 


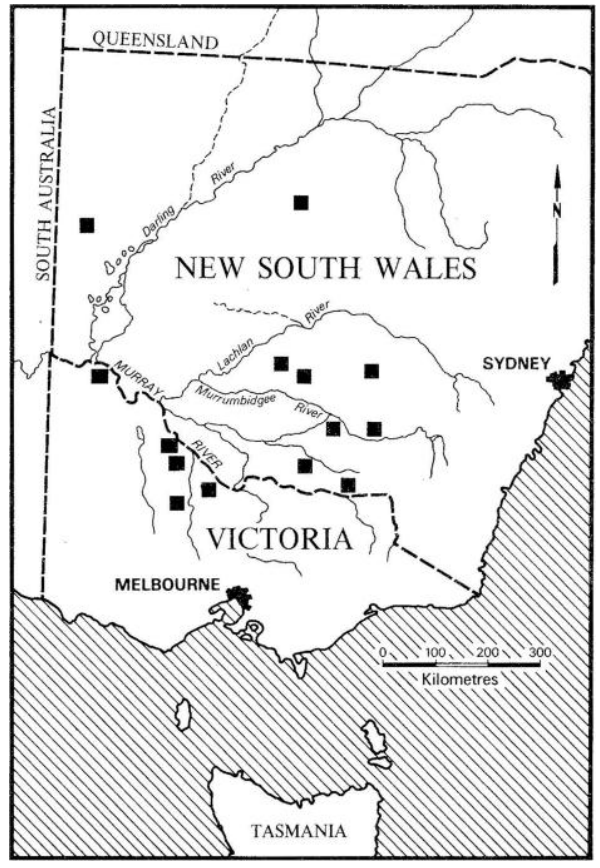

Fig 8 